\title{
Studies on the Phosphoproteins of Brain
}

\section{PHOSPHORYLSERINE SEQUENCES IN BRAIN PHOSPHOPROTEIN*}

\author{
BY P. J. HEALD $\dagger$ \\ Department of Biochemistry, Institute of Psychiatry (British Postgraduate Medical Federation, \\ University of London), Maudsley Hospital, London, S.E. 5
}

\section{(Received 24 January 1961)}

In a previous paper it was reported that a phosphoprotein fraction isolated from brain was capable of accepting radioactive phosphate in a suitable phosphorylating system and that the phosphate incorporated could subsequently be isolated as phosphorylserine (Heald, 1961a). It was later shown (Rose \& Heald, 1961) that this phosphoprotein fraction was attacked, to a limited degree, by a specific phosphoprotein phosphatase isolated from brain.

These properties are shared with the phosphoproteins casein and phosvitin, which have been shown to contain sequences of phosphorylserine residues of the type (Ser-P) $n$, where $n$ can range up to at least 6 (Williams \& Sanger, 1959). These authors suggested (cf. also Rabinowitz \& Lipmann, 1960) that sequences of this type were responsible for the ability of such phosphoproteins to act as phosphate acceptors for protein phosphokinases of mammalian origin (Burnett \& Kennedy, 1954) or from yeast (Rabinowitz \& Lipmann, 1960). Since preparations of cerebral phosphoprotein also accepted phosphate in a suitable phosphorylating system and yielded phosphorylserine on acid hydrolysis (Heald, 1961 a) it was of interest to see whether sequences of phosphorylserine similar to those existing in casein and phosvitin were present. The results described below show that such sequences do in fact exist in the brain phosphoproteins.

\section{MATERIALS AND METHODS}

Tissue preparations. Slices of guinea-pig cerebral cortex were cut and incubated with radioactive phosphate as described by Heald (1959). After incubation the slices were removed and dispersions made and centrifuged to yield a 'nuclear fraction' and a 'supernatant' under the conditions described in that paper. After separation the fractions were precipitated by the addition of trichloroacetic acid $(10 \%, w / v)$ and extracted to yield a residue containing phosphoprotein as described previously (Heald, 1957).

Preparation of partial acid hydrolysate. Phosphoproteins were partially hydrolysed by incubation for $18 \mathrm{hr}$. at $37^{\circ}$

* Part 2: Heald (1961 a).

$\dagger$ Present address: Twyford Laboratories Ltd., Twyford Abbey Road, London, N.W.10. with conc. $\mathrm{HCl}$. The $\mathrm{HCl}$ was removed under vacuum over $\mathrm{P}_{2} \mathrm{O}_{5}$ and $\mathrm{KOH}$ and the residues were dissolved in small volumes of water. With partial hydrolysates of phosvitin these solutions could be used directly for electrophoresis. With partial hydrolysates of other proteins the hydrolysates were first treated as described by Flavin (1954). Thus the aqueous solutions, usually purple in colour, were run on to a column $\left(2 \mathrm{~cm} .^{2} \times 12 \mathrm{~cm}\right.$.) of Dowex $50\left(\mathrm{H}^{+}\right.$form; 80-100 mesh) and eluted with water until the purple band had been removed. This also removed some phosphorylated peptides but the majority remained on the column and were removed with $150 \mathrm{ml}$. of $0.05 \mathrm{~N}-\mathrm{HCl}$. The eluates were reduced to small volume in a rotary evaporator at $35^{\circ}$ and the final traces of water and $\mathrm{HCl}$ were removed under vacuum and over $\mathrm{P}_{2} \mathrm{O}_{5}$ and $\mathrm{KOH}$. Peptides containing phosphorylserine were further partially hydrolysed to yield phosphorylserine by heating at $100^{\circ}$ for $6 \mathrm{hr}$. in $2 \mathrm{~N}-\mathrm{HCl}$. Total hydrolysis to yield amino acids was accomplished by heating at $100^{\circ}$ for $24 \mathrm{hr}$. in $6 \mathrm{~N}-\mathrm{HCl}$.

Electrophoresis. Samples were subjected to electrophoresis on Whatman no. 20 or $3 \mathrm{MM}$ paper with formic acid-water $(1: 4, v / v)$, adjusted to $\mathrm{pH} 1.5$ with $\mathrm{NaOH}$, as the buffer system (Williams \& Sanger, 1959). Papers $(50 \mathrm{~cm}$. long) were placed in horizontal electrophoresis tanks and a potential of $8-10 \mathrm{v} / \mathrm{cm}$. was applied for $16-18 \mathrm{hr}$. at $2^{\circ}$. The papers were then removed and dried at $60^{\circ}$. Phosphorylated peptides were located with ninhydrin $(0 \cdot 1 \%, \mathrm{w} / \mathrm{v})$ in acetone, and with the ferric chloride-sulphosalicylic acid reagent of Wade \& Morgan (1954) for the detection of phosphates. To prepare sufficient quantities of peptides for further examination, suitable guide strips were used to indicate the position of the peptides on the bulk of the paper, and the corresponding areas were cut out and eluted by capillary elution with water.

Chromatography. Amino acids were separated on Whatman no. 1 paper with phenol-water $(60: 40, \mathrm{w} / \mathrm{v})$ and butan-1-ol-acetic acid-water (40:10:50, by vol.) as the solvents. Phosphorylserine was separated from inorganic phosphate by chromatography on paper with the acetateethanol solvent of Kennedy \& Smith (1954).

Phosphoproteins and albumin. Phosvitin was obtained from Nutritional Biochemicals Corp., Calif., U.S.A. All the phosphorus was liberated by alkali in $18 \mathrm{hr}$. (Rose \& Heald, 1961). Pepsin, twice recrystallized, was obtained from the Sigma Chemical Co. $\alpha$-Casein, prepared from Hammarsten casein (Hopkin and Williams Ltd.) was a gift from Mr S. P. R. Rose. Crystalline bovine serum albumin was obtained from Armour Laboratories Ltd. Phospholipoprotein from ox brain was prepared as described by Heald $(1961 a), 288 \mathrm{~g}$. of brain being used for each preparation. The content of alkali-labile phosphate was 
$0.05-0.06 \%$ of the dry wt. for each preparation. Before partial hydrolysis lipids were removed by extraction with ether-ethanol $(1: 3, \nabla / v)$ for $2-3 \mathrm{hr}$. at room temperature and the lipid-free residue was air-dried.

Radioactive phosphate. This was obtained as carrier-free radioactive phosphate from The Radiochemical Centre, Amersham, Bucks.

\section{Analytical methods}

Inorganic and total phosphorus. These were determined by methods described by Heald (1959).

Serine. This was determined in the total hydrolysates of the serine peptides by the method of Troll \& Cannan (1953). Loss of serine during hydrolysis was corrected for by including standard serine solutions in the procedure.

Determination of radioactivity. Samples in solution (10 ml.) were counted with a $\mathrm{M} 6 \mathrm{H}$ liquid counter (20thCentury Electronics Ltd.). Radioactivity on paper chromatograms was determined either by cutting out areas and counting under an end-window counter or by means of a gas-flow counter fitted to an automatic recording unit.

\section{RESULTS}

Although the buffer system described by Williams \& Sanger (1959) ensured that only phosphorylserine, inorganic phosphate, pyrophosphate or peptides containing two or more phosphate groups migrated towards the anode, the separations obtained by these authors made use of high-voltage electrophoresis. Since this type of apparatus was not available the possibility of similar separations being obtained at low voltage was examined.

When a partial hydrolysate of phosvitin was subjected to electrophoresis for $6-7 \mathrm{hr}$. under the conditions described a series of 'bands' were detected which reacted with both peptide and phosphate reagents. Better separation was obtained if the electrophoresis was carried out for 16-18 hr. at $2^{\circ}$. The major ninhydrin-positive bands corresponded exactly with those containing phosphate (Fig. 1). In all, six bands were detected. Phosphorylserine migrated at the same rate as band 2, and inorganic phosphate migrated to a position slightly in front of band 6, causing some contamination. Pyrophosphate migrated ahead of inorganic phosphate. When bands 1-5 were separately eluted and again subjected to electrophoresis only one component, migrating at the same rate as the parent band, was obtained from each fraction. The bands were partially hydrolysed by conc. $\mathrm{HCl}$ and the partial hydrolysates were again separated by electrophoresis at $\mathrm{pH} \mathbf{1 . 5}$. Bands 3-5 yielded fractions migrating at the same rate as the phosphorylserine in addition to the intermediate bands (Fig. 2). Band 1 was partially stable but also yielded phosphorylserine and a trace of band 3, whereas band 2 was largely stable but yielded a trace of band 1. Chromatography of the total acid hydrolysates showed that serine was the only major detectable amino acid present in each fraction together with possible traces of glutamic acid. The major bands therefore represent phosphoserine peptides of the type described by Williams \& Sanger (1959) probably intermixed, particularly in bands 1 and 2, with phosphorylserine peptides of a higher molecular weight but partially dephosphorylated as a result of the acid hydrolysis. The presence of such dephosphorylated peptides is supported by estimations of the serine/ phosphorus ratio in each fraction. These were: band $1,2 \cdot 15$; band $2,1 \cdot 72$; band $3,1 \cdot 22$; band 4 , 1.27 ; band $5,1 \cdot 19$. The ratio of serine to phosphate exceeded unity in all fractions and tended to decrease as the complexity of the phosphopeptide increased. This trend would be expected since the peptides represented by band 5 are more likely to be closer to the size of the actual sequence in the phosphoprotein than are the peptides in band 1 . Since the bands contained only serine and phos-

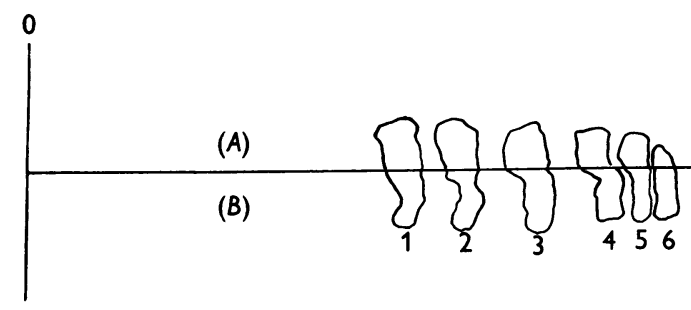

Fig. 1. Separation of phosphopeptides from acid hydrolysates of phosvitin by electrophoresis in formic acid $(20 \%$, $\mathrm{v} / \mathrm{v})-\mathrm{NaOH}, \mathrm{pH} \mathrm{1.5}$. Conditions were as described in the Materials and Methods section. (A) Sprayed with ninhydrin; $(B)$ sprayed with the phosphate reagents of Wade \& Morgan (1954). This and the following Figures are copies of tracings taken from the original electrophoretograms.

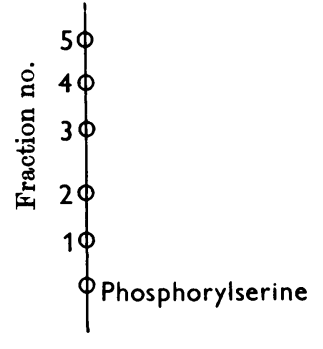

Relative positions occupied by original fractions

Fig. 2. Electrophoresis of fractions 1-5 (Fig. 1) after further partial acid hydrolysis. System was as described in Fig. 1. Electrophoresis was for $6 \mathrm{hr}$. at $10 \mathrm{v} / \mathrm{cm}$. The fractions were detected with ninhydrin. Broken lines indicate the position of areas of weak reaction. 
phorus it is considered that a serine/phosphorus ratio greater than unity is indicative of the presence of polyserylpeptides in which only some of the seryl residues are phosphorylated. The degree of polymerization could not be assessed, but, by analogy with the conclusions of Williams \& Sanger (1959), bands 3, 4, 5 and 6 must represent a series in which (Ser-P) ${ }_{2}$ is the minimum. It is not known whether the peptides described by these authors contained equivalent amounts of phosphorus and serine.

Partial hydrolysis of $\alpha$-casein and of unfractionated casein also yielded phosphopeptides migrating at a rate similar to those from phosvitin (Fig. 3). In most instances bands 5 and 6 were not visible. This was not due to the smaller amounts of phosphorylated fragments derived from casein, containing $0.8-0.9 \%$ of $P$, as compared with phosvitin containing $8-10 \%$ of $\mathrm{P}$, since partial hydrolysis of $0.5 \mathrm{~g}$. of casein and a separation of the total phosphopeptides in the hydrolysate failed to reveal band 6 , though band 5 was then visible. On elution and total hydrolysis, serine was again the major amino acid detected, accompanied by smaller amounts of alanine, leucine and glutamic acid. Similar amino acids were found by Williams \& Sanger (1959) in fractions from casein migrating at rates intermediate to the main phosphoseryl peptides.

The above experiments showed that low-voltage electrophoresis, though not achieving the degree of resolution of the high-voltage system, was nevertheless capable of separating groups of peptides containing phosphorylserine polymers, from partial hydrolysates of casein and phosvitin. It was therefore used to examine brain phosphoprotein.

Partial hydrolysis of brain phosphoproteins. Lipid-free preparations of brain phosphoprotein were partially hydrolysed and the phosphopeptides separated on Dowex 50 and subjected to electrophoresis. The fractions obtained migrated at rates similar to those obtained from casein and phosvitin (Fig. 3). Four bands were visible. However, the quantities of phosphoprotein phosphorus were extremely small and separations of the type shown in Fig. 3 necessitated placing all the phosphopeptides derived from a fraction (representing 100 $150 \mathrm{~g}$. of fresh brain) on to the paper. To reduce laborious preparations the technique of isotope dilution was used. Phosphoserine from brain phosphoproteins is radioactive when derived from tissues incubated with ${ }^{32} \mathrm{P}$ (Heald, 1958). Slices of guinea-pig cerebral cortex were incubated with radioactive phosphate and the phosphoprotein fractions obtained and partially hydrolysed in the presence of phosvitin (about $20 \mathrm{mg}$. of phosvitin for $700 \mathrm{mg}$. of slices). The partial hydrolysates were then subjected to electrophoresis at $\mathrm{pH} \mathbf{1 \cdot 5}$. When the paper strips were scanned in an automatic scanner the areas of radioactivity corresponded closely with the major ninhydrin-reacting bands present (Fig. 4). To determine whether the radioactivity represented phosphoseryl peptides, the areas corresponding to the bands were eluted and partially hydrolysed in $2 \mathrm{~N}-\mathrm{HCl}$ at $100^{\circ}$ in the presence of carrier phosphorylserine. The hydrolysates were then separated both by electrophoresis and by chromatography on paper. The areas containing phosphorylserine were removed and counted; they contained up to $30 \%$ of the radioactivity added to the paper (Table 1). The remaining activity was concentrated largely in the areas corresponding to inorganic phosphate. Inclusion of radioactivity in phosphorylserine was not due to chemical exchange since an experiment in which phosvitin was partially hydrolysed with $40 \mu \mathrm{C}$ of inorganic [ ${ }^{32} \mathrm{P}$ ]phosphate revealed radioactivity, after separation of the phosphopeptides, only in the areas of ortho- and pyro-phosphate.

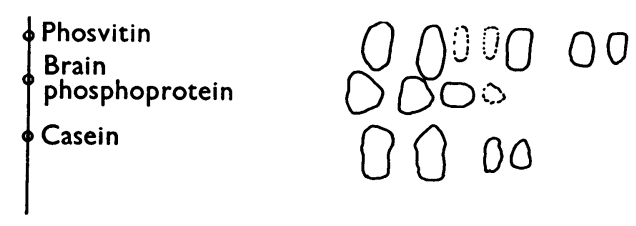

Fig. 3. Comparisons of the rates of migration of phosphopeptides derived from brain phosphoprotein with phosphopeptides derived from $\alpha$-casein and phosvitin. Separation and conditions were as described in Fig. 1.

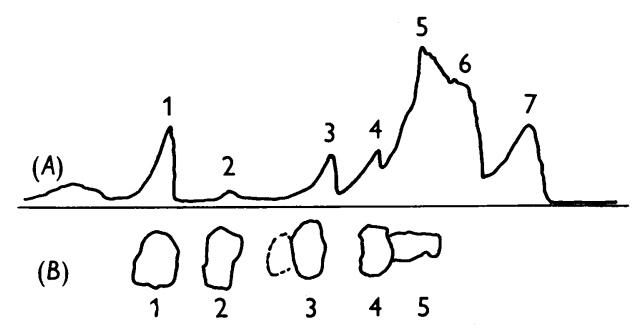

Fig. 4. Radioactivity in phosphopeptides separated from partial acid hydrolysates of radioactive brain phosphoprotein, admixed with phosvitin before partial hydrolysis. Conditions were as described in Fig. 1. (A) Tracing of the curve of radioactivity drawn by an automatic recording apparatus; $(B)$ position of the phosphopeptides detected with ninhydrin. Peaks 6 and 7 correspond to the position of orthophosphate and pyrophosphate respectively. For this recording peak 7 was recorded with the apparatus set for a full-scale deflexion with 1000 counts/sec. and the remainder with a setting for a full-scale deflexion with 300 counts/sec. The highest point of peak 5 corresponds approximately to an activity of 200 counts/sec. 
Table 1. Radioactivity of phosphorylserine derived from phosphopeptides in partial acid hydrolysates of brain phosphoprotein

\begin{tabular}{|c|c|c|c|c|}
\hline $\begin{array}{l}\text { Source of tissue } \\
\text { phosphoprotein }\end{array}$ & $\begin{array}{c}\text { Fraction } \\
\text { no. }\end{array}$ & $\begin{array}{l}\text { Counts/min. } \\
\text { added to } \\
\text { paper }\end{array}$ & $\begin{array}{c}\text { Counts/min. } \\
\text { in phosphoryl- } \\
\text { serine }\end{array}$ & $\begin{array}{l}\text { Activity in } \\
\text { phosphoryl- } \\
\text { serine as \% of } \\
\text { activity added }\end{array}$ \\
\hline 'Nuclear' fraction & $\begin{array}{l}1 \\
2 \\
3 \\
4 \\
5^{*} \\
6^{*}\end{array}$ & $\begin{array}{r}1236 \\
2415 \\
660 \\
452 \\
1110 \\
4200\end{array}$ & $\begin{array}{l}383 \\
611 \\
176 \\
137 \\
212 \\
103\end{array}$ & $\begin{array}{r}31 \cdot 0 \\
25 \cdot 0 \\
26 \cdot 6 \\
30 \cdot 3 \\
19 \cdot 3 \\
2 \cdot 5\end{array}$ \\
\hline 'Supernatant' fraction & $\begin{array}{l}1 \\
\mathbf{2} \\
\mathbf{3} \\
\mathbf{4}\end{array}$ & $\begin{array}{r}1000 \\
3040 \\
339 \\
1540\end{array}$ & $\begin{array}{l}247 \\
775 \\
228 \\
444\end{array}$ & $\begin{array}{l}24 \cdot 7 \\
25 \cdot 5 \\
67 \cdot 0 \dagger \\
28 \cdot 6\end{array}$ \\
\hline
\end{tabular}

* Includes inorganic phosphate contamination of original fractions.

$\dagger$ High percentage count is anomalous.

\section{DISCUSSION}

The results presented above establish the existence, in brain phosphoproteins, of sequences of phosphorylserine residues of a type similar to those found in casein and phosvitin. This conclusion is based on the following : $(a)$ partial acid hydrolysis of brain phosphoprotein yielded phosphopeptides migrating at rates similar to those from phosvitin and casein; (b) when brain phosphoprotein was made radioactive by incorporation of radioactive phosphate and partially hydrolysed in the presence of phosvitin the phosphoseryl peptides isolated contained radioactive phosphorus; $(c)$ when these peptides were hydrolysed to yield phosphorylserine, the phosphorylserine separated both chromatographically and electrophoretically was radioactive. In the absence of isolation and analysis of the individual peptides the presence or absence of other amino acids cannot be decided upon conclusively, but the similarities of migration on electrophoresis at $\mathrm{pH} \mathbf{1 . 5}$ of the peptides from brain with those from phosvitin and casein suggest that other amino acids formed only a small fraction of the total peptide.

Previous work (Heald, 1959) has shown that when the intact tissue is electrically stimulated only the phosphoprotein appearing in the 'nuclear' fraction increased in radioactivity, whereas that present in the 'supernatant' was not affected. Since both the 'nuclear' and the 'supernatant' fraction (the latter containing mitochondria) contained phosphoproteins yielding phosphoseryl peptides upon hydrolysis, it is considered that the distinction in metabolism resulting from the electrical stimulus is more probably a reflexion of function than of type. The function of cellular phosphoproteins of a non-enzymic type is not known, though suggestions of involvement in ion transport (Heald, 1960, 1961 b) or water movement (Judah, 1960) have been made. In these connexions it seems highly significant that the presence of sequences of negatively charged phosphate groups places the phosphoproteins of brain in the category of natural polyelectrolytes which in solution are capable of acting as do ion-exchange resins. Since brain phosphoproteins are capable of being both phosphorylated and dephosphorylated (Heald, 1961 $a$; Rose \& Heald, 1961) by cerebral enzymes, it is suggested that in the cell they operate as metabolically activated natural ionexchange materials, the results of the activation being the transport of ions or water across cellular membranes. The implications of this type of system are being investigated.

\section{SUMMARY}

1. By use of low-voltage paper electrophoresis of partial acid hydrolysates of phosphoproteins, it has been confirmed that casein and phosvitin contain sequences of phosphorylseryl residues of the type (Ser-P) $)_{n}$.

2. The fractions separated by electrophoresis, though migrating as single components, were not pure and contained phosphoseryl peptides linked with other amino acids, probably glutamic acid and partially dephosphorylated phosphoseryl peptides.

Bioch. 1961, 80 
3. Phosphoproteins of brain contain similar phosphoseryl sequences. This has been shown both by comparison of rates of migration of phosphopeptides separated from partial hydrolysates and by a technique involving isotopic dilution.

4. The results are discussed in relation to the possible metabolic role of brain phosphoproteins in the intact tissue.

I am indebted to Dr J. Williams for helpful correspondence during the initial stages of this work, and Dr M. J. H. Smith, Kings College Hospital Medical School, for permission to use an automatic recording apparatus (constructed on the premises) for the detection of radioactivity in chromatographic strips.

\section{REFERENCES}

Burnett, G. \& Kennedy, E. P. (1954). J. biol. Chem. 211, 969.

Flavin, M. (1954). J. biol. Chem. 210, 771.
Heald, P. J. (1957). Biochem. J. 66, 659.

Heald, P. J. (1958). Biochem. J. 68, 580.

Heald, P. J. (1959). Biochem. J. 73, 132.

Heald, P. J. (1960). Phosphorus Metabolism of Brain. Oxford: Pergamon Press Ltd.

Heald, P. J. (1961 a). Biochem. J. 78, 340.

Heald, P. J. (1961b). Proc. 4th int. Symp. Neurochem. Oxford: Pergamon Press Ltd.

Judah, J. D. (1960). Nature, Lond., 187, 506.

Kennedy, E. P. \& Smith, S. W. (1954). J. biol. Chem. 207, 153.

Rabinowitz, M. \& Lipmann, F. (1960). J. biol. Chem. 235, 1043.

Rose, S. P. R. \& Heald, P. J. (1961). Biochem. J. (in the Press).

Troll, W. \& Cannan, R. K. (1953). J. biol. Chem. 200, 806.

Wade, H. E. \& Morgan, D. M. (1954). Biochem. J. 49, 286.

Williams, J. \& Sanger, F. (1959). Biochim. biophys. Acta, 33, 294.

Biochem. J. (1961) 80, 514

\title{
The Action of a Lactobacillus bifidus Dextranase on a Branched Dextran
}

\author{
By R. W. BAILEY, D. H. HUTSON AND H. WEIGEL \\ Chemistry Department, Royal Holloway College, University of London, Englefield Green, Surrey
}

(Received 23 February 1961)

It has been shown that an extracellular dextranase of a rumen strain of Lactobacillus bifidus, when incubated with the essentially unbranched dextran of Streptococcus bovis, produces isomaltotriose, isomaltotetraose, isomaltopentaose, isomaltohexaose and traces of isomaltoheptaose, but no glucose or isomaltose (Bailey \& Clarke, 1959). A study of the action of the $L$. bifidus dextranase on various dextrans revealed that the mixture of oligosaccharides produced varied with the type, and degree of branching, of the dextran (Bailey, Hutson \& Weigel, 1960). We have now examined in detail the action of this dextranase on the branched dextran elaborated by Leuconostoc mesenteroides (Betacoccus arabinosaceous, Birmingham strain).

\section{EXPERIMENTAL}

Dextranase. The dextranase was isolated from cell-free culture fluid of a rumen strain of Lb. bifidus by one of us (R.W.B.) in the Laboratories of the Plant Chemistry Division, D.S.I.R., Palmerston North, New Zealand, according to the method described by Bailey \& Clarke (1959).

Dextrans. Leuconostoc mesenteroides (Birmingham strain) dextran was synthesized from sucrose. The dextran was from the same batch as was that used for structural studies of the dextran, which was shown to contain, as well as $\alpha$-1:6-linkages, $12-15 \%$ of $\alpha$-1:3-branch linkages (Barker, Bourne, Bruce, Neely \& Stacey, 1954). A virtually unbranched dextran (Bailey, 1959) was isolated from a sucrose-containing culture of $S$. bovis (strain I) (Bailey \& Oxford, 1958).

Paper chromatography and ionophoresis. The solvents used for paper chromatography were: $(a)$ the upper layer of ethyl acetate-water-pyridine (2:2:1, by vol.) (Jermyn \& Isherwood, 1949); (b) ethyl acetate-water-pyridineacetone (Malpress \& Hytten, 1958); (c) upper layer of butanol-ethanol-water (4:1:5, by vol.); (d) ethyl acetateacetic acid-water $(9: 2: 2$, by vol.); (e) butanol-benzenepyridine-water (5:1:3:2, by vol.). Ionophoresis was carried out at about $50 \mathrm{v} / \mathrm{cm}$. in borate solution, $\mathrm{pH} 10$ (Foster, 1953), and in molybdate solution, pH 5.5 (Bourne, Hutson \& Weigel, 1959). It will be noticed that some of the $M_{S}$ (mobility with respect to sorbitol) values reported here differ slightly from those reported earlier. This is due to the application of smaller quantities, thus allowing a more accurate determination of the rates of migration. In all cases comparison was made with known compounds.

The reagents used for the detection of compounds were: (a) silver nitrate in acetone-ethanolic sodium hydroxide (Trevelyan, Procter \& Harrison, 1950); (b) aniline hydrogen phthalate (Partridge, 1949); (c) p-anisidine-HCl (Hough, Jones \& Wadman, 1950); (d) aniline-diphenylamine- 